\title{
Association between menthol-flavoured cigarette smoking and flavoured little cigar and cigarillo use among African-American, Hispanic, and white young and middle-aged adult smokers
}

\author{
K Sterling, ${ }^{1}$ C Fryer, ${ }^{2}$ I Pagano, ${ }^{3}$ D Jones, ${ }^{1}$ P Fagan ${ }^{4}$
}

${ }^{1} S$ chool of Public Health, Georgia State University, Atlanta, Georgia, USA ${ }^{2}$ University of Maryland, College Park, Maryland, USA ${ }^{3}$ University of Hawaii at Manoa, Honolulu, Hawaii, USA ${ }^{4}$ Univeristy of Arkansas for Medical Sciences, Fay W. Boozman College of Public Health, USA

\section{Correspondence to} Dr K Sterling, Georgia State University, One Park Place, Suite 715, Atlanta, GA 30303, USA; ksterling@gsu.edu

Received 26 May 2016 Accepted 7 September 2016 Published Online First 7 October 2016

\section{CrossMark}

To cite: Sterling K, Fryer C, Pagano I, et al. Tob Control 2016;25:ii21-ii31.

\section{ABSTRACT}

Objectives Flavour additives in cigarettes and little cigars and cigarillos (LCCS), which influence smokers' risk perceptions, may reinforce dual flavoured tobacco use. We examined the association among mentholated cigarette use, risk perceptions for flavour additives in LCCs and flavoured LCC smoking behaviour.

Methods Data from a national probability sample of 964 young and middle-aged adult current cigarette smokers were analysed. Multinomial logistic regression models examined the relationship among mentholated cigarette smoking, risk perceptions and current flavoured LCC use for the analytic sample and gender and race/ethnicity.

Results Daily menthol cigarette smokers, compared to occasional, non-menthol smokers, had increased odds of flavoured LCC smoking $(\mathrm{OR}=1.75,95 \% \mathrm{Cl} 1.02$ to 2.98). This relationship was found for males, blacks/ African-Americans and Hispanics/Latinos $(p<0.05)$. Positive perceptions of menthol-flavoured additives in LCCs was associated with increased odds of flavoured LCC use among the analytic sample, males and blacks/ African-Americans $(p<0.05)$. Positive perceptions for clove-flavoured, spice-flavoured and alcohol-flavoured additives were also associated with flavoured LCC use among the analytic sample $(p<0.05)$.

Conclusions Use of menthol-flavoured cigarettes and positive perceptions about menthol-flavoured and other flavour additives in LCCs may contribute to dual use with flavoured LCCs among adult cigarette smokers, specifically those from vulnerable populations.

\section{INTRODUCTION}

Eliminating characterising flavours in newly deemed tobacco products, such as little cigars and cigarillos (LCCs), to curtail their usage among vulnerable populations (eg, young people, blacks/ African-Americans, Hispanics) and to protect the public's health is a critically important issue in tobacco control regulatory sciences. In 2009, the Family Smoking Prevention and Tobacco Control Act (FSPTCA) banned characterising flavours in cigarettes. Menthol-flavoured cigarettes were excluded from the ban, however. Despite recommendations to ban menthol cigarettes to protect the public's health, ${ }^{1}$ these products remain on the market. In May 2016, the Food and Drug Administration (FDA) extended its regulatory authority to all cigars, including LCCs, but did not ban characterising flavours in these products. ${ }^{2}$ The FDA announced its intentions to propose a product standard that would, if finalised, eliminate characterising flavours-excluding menthol-in LCCs. ${ }^{2}{ }^{3}$ As scientific debates about the public health impact of menthol-flavoured cigarettes continues, the availability of menthol-flavoured cigarettes and flavoured cigars may contribute to the growing popularity of these products among young people, particularly black/African-Americans and Hispanic/ Latinos who, compared with whites, are at increased risk for use. ${ }^{45}$

Characterising flavour additives mask the bitter flavour, irritation, pain and harshness of tobacco and nicotine ${ }^{6}$ and may increase the appeal of tobacco products among young people. ${ }^{7}$ Unlike characterising flavours that were banned in the FSPTCA, menthol flavour has physiological and pharmacological effects that increase and reinforce smoking. ${ }^{1}{ }^{8-10}$ Use of menthol-flavoured cigarettes may facilitate progression to established cigarette smoking in young smokers. ${ }^{147}{ }^{11}$ Further studies have indicated that use of any menthol-flavoured tobacco product (eg, e-cigarettes, cigars) is associated with a two-fold risk of dual use with another flavoured tobacco product. ${ }^{12}$ LCCs are no exception to this finding. In a study of college students in the southeastern USA, Sterling et $a l^{13}$ found that menthol cigarette smokers were almost twice as likely as non-menthol cigarette smokers to report LCC smoking. LCCs are often available in characterising flavours similar to those once found in cigarettes. ${ }^{14}{ }^{15}$ The association between mentholflavoured cigarettes and LCCs likely reflects a preference for characterising flavours, especially among blacks/African-Americans and Hispanics/Latinos, who are more likely and to reject the bitter flavour of nicotine due to their taster status. ${ }^{16}$ Lack of regulation of all characterising flavours (including menthol) may contribute to product use among these vulnerable populations.

In addition to characterising flavours, understanding the impact of consumers' risk perceptions of flavoured tobacco products on smoking behaviour is important for informing the FDA's regulations. ${ }^{17}$ Risk perceptions are proximal predictors of smoking and quitting behaviour. ${ }^{18} 19$ Recently Brennan et $a l^{20}$ reported that youth and young adults who held favourable beliefs about menthol were at increased risk of initiating menthol cigarette smoking and use of other tobacco products (including cigars and little cigars). Beyond this study, to the best of our knowledge, no other study has examined consumers' risk perceptions of flavour 
additives in LCCs and its association with flavoured LCC use. Increasing our understanding of the relationship between perceptions about flavour additives in LCC tobacco and flavoured LCC smoking may shed light on the potential underlying mechanism by which characterising flavours influences flavoured tobacco product use.

We sought to examine the association of menthol cigarette smoking with current use of flavoured and unflavoured LCCs. This study goes beyond the study by Sterling et al by examining the association among a national probability sample of black/ African-American, Hispanic/Latino and white young and middle aged adult cigarette smokers. In addition, we examined the association between risk perceptions about flavour additives in LCC tobacco and current flavoured/unflavoured LCC use. We stratified our analyses by race/ethnicity and gender to understand variations among groups. We hypothesised that (1) daily use of menthol cigarettes is associated with increased odds of flavoured LCC smoking; (2) positive perceptions (ie, less harmful to smoke) of flavour additives in LCC tobacco are associated with increased odds of flavoured LCC smoking; and (3) positive associations for menthol cigarette use, risk perceptions and flavoured LCC use will be found among blacks/African-Americans, Hispanics/Latinos and males; groups that are at risk for flavoured tobacco use. Study findings may increase our understanding of the abuse liability of flavoured tobacco products among young people; the role of risk perceptions on flavoured tobacco use and provide valuable information on the harms of flavour additives to the FDA, who has authority to deem the regulation of all flavoured tobacco products.

\section{METHODS}

\section{Sample and procedure}

An online survey, conducted by GfK, was used to collect LCC use behaviours and correlates among a sample of black/ African-American, Hispanic/Latino and white cigarette smokers, aged 18-44 years, residing in the USA $(n=1018)$. A blended sample comprising both the GfK KnowledgePanel and opt-in panel participants was obtained for this study. To obtain the sample, GfK sampled households from its KnowledgePanel, a probability-based web panel designed to be representative of the USA. GfK also contracted with an opt-in panel vendor to obtain additional cases to increase the overall sample size. Using their proprietary calibration process, GfK applied calibrated weights to ensure that the resulting blended sample represented the target population more effectively. Cigarette smokers aged 3544 were included to increase the sample size of smokers from different racial/ethnic groups. GfK recruited equivalent numbers of participants across racial/ethnic groups to identify and compare variations in the patterns of LCC use. Among the 1018 respondents, $32.1 \%$ were black/African-American, 32.4\% Hispanic/Latino and $35.5 \%$ white cigarette smokers.

The survey consisted of two stages: (1) initial screening for respondents' age and current cigarette smoking status and (2) the main survey. Of the KnowledgePanel participants, 1477 were screened for this study, and of those $42.3 \%(n=625)$ completed the screener. Of those that completed the screener, $85.1 \%(n=532)$ were eligible and completed the main survey. The remaining participants $(n=486)$ came from the opt-in panel. According to $\mathrm{GfK}^{21}$ the eligibility rate for the main survey for opt-in panel cases who were screened was $85.4 \%$. GfK's opt-in panel provider does not record how many screening invitations were sent out, however. Thus, the screener completion rate for the opt-in panel participants cannot be calculated. However, GfK estimates that typical screener completion rates for the opt-in panel is $5-8 \% .^{21}$ We compared the weighted demographics of the sample with current smokers from the Behavioral Risk Factor Surveillance System annual survey and found that the smoking rates for racial/ethnic groups by demographic factors (age, gender, education, region) were similar. The online survey was pretested and administered to the sample from May to June 2015. The Institutional Review Board at Georgia State University approved the study.

\section{Survey measures}

Sociodemographic factors

We assessed respondents' age (18-24, 25-34 and 35-44 years), gender (male, female), race/ethnicity (white, black/ African-American, non-Hispanic and Hispanic/Latino), region of the country (Northeast, Midwest, South, West), educational attainment (less than high school, high school graduate, some college, and college graduate or advanced degree), household income $(<\$ 15000, \$ 15000-\$ 40000, \$ 40000-\$ 75000$ and $\geq \$ 75000$ ) and employment status (working, not working but looking for work, and not working, not looking for work).

\section{Cigarette smoking behaviour}

Consistent with the measures found in other national tobacco surveillance systems, ${ }^{22}$ cigarette smoking frequency was assessed by asking if respondents smoked cigarettes 'every day' (referred to as daily use) or 'some days' (referred to as occasional use). Respondents also reported their usual brand of cigarettes smoked (mentholated, non-mentholated, no usual brand). Using these two variables, we created four categories of smokers for the primary independent variable: daily menthol smoking, daily non-menthol smoking, occasional menthol smoking and occasional non-menthol smoking.

\section{LCC smoking behaviour}

Focus group findings on LCC smoking behaviour and risk perceptions of LCC smoking were used to modify established cigarette use measures and develop new LCC smoking and risk perception measures that could be used among diverse groups. $^{23-25}$ Respondents were asked if they had ever tried a LCC (yes/no). Respondents who reported no LCC use were considered cigarette smokers, non-LCC users. Respondents who were lifetime LCC users, and did not report past 30-day use, were also considered cigarette smokers, non-LCC users. To assess the type of LCC used, those who reported LCC smoking were asked, 'Did you smoke the little cigar or cigarillo without marijuana (also known as weed, pot, loud, etc) inside of it? (yes/ no); with marijuana inside it? (yes/no); and with and without marijuana inside it? (yes/no)'. Current LCC use was assessed by asking respondents if they now smoke LCC-tobacco, LCC-blunts, or LCC-tobacco and LCC-blunts daily, occasionally or not at all. Respondents who said they only smoked LCCs without marijuana were classified as LCC-tobacco smokers; those who smoked LCCs with marijuana inside were LCC-blunt smokers; and those who used LCC with tobacco and marijuana were LCC-poly smokers.

\section{Current flavoured LCC use}

LCC-tobacco and LCC-poly users were asked 'During the past 30 days, were any of the LCCs that you smoked flavoured with menthol, mint, clove, spice, candy, fruit, chocolate, alcohol (such as wine or cognac) or other sweets?' (yes/no). LCC-blunt and LCC-poly users were asked a similar question phrased 
specifically for LCC-blunt smoking. These items were used to create two groups of smokers: unflavoured and flavoured LCC smokers. Flavoured LCC users were those who used any flavoured LCC (either LCC-tobacco, LCC-blunts or LCC-polyuse), whereas unflavoured LCC users smoked any tobacco flavoured LCC product.

\section{Other tobacco use}

Other tobacco use was assessed by asking respondents if they had smoked, in the past 30 days, large cigars, hookah tobacco or used e-cigarettes/tanks/vaporizers (yes/no).

\section{Risk perceptions}

All survey respondents were asked to assess the harmfulness of seven flavour additives in LCCs (or LCC flavours) compared with tobacco-flavoured LCCs. Using a scale from 1 (less harmful) to 5 (most harmful), respondents ranked the harmfulness of each of the following seven categories of flavoured LCCs: menthol, clove, spice, candy, fruit, chocolate and alcohol flavoured.

\section{Analyses}

Data analyses were conducted using SAS, V 9.2. Though 1018 respondents completed the survey, those who reported smoking no usual brand of cigarettes $(n=54)$ were excluded from the analysis, resulting in a final analytic sample of 964 smokers. Descriptive and bivariate analyses were conducted to assess the weighted prevalence of dual use of flavoured LCC and menthol/ non-menthol smoking. We used multinomial logistic regression models to examine the association between menthol/nonmenthol smoking frequency and the outcomes (1) flavoured LCC use versus cigarette, non-LCC use (reference group) and (2) unflavoured LCC use versus cigarette, non-LCC use (reference group). Multinomial logistic regression models also assessed the association between each of the seven risk perception variables independently and flavoured/unflavoured LCC use. The reference group for each risk perception variable was 'as harmful'. All analyses controlled for age, gender, race/ethnicity, household income, educational attainment, employment status and other tobacco use. We ran models separately for gender and racial/ethnic groups. All data presented in the manuscript are weighted and complex sampling procedures were used to adjust for sampling in all analyses.

\section{RESULTS}

\section{Prevalence of dual menthol/non-menthol cigarette and flavoured LCC use}

Table 1 presents the sociodemographic characteristics and prevalence of menthol cigarette and LCC smoking behaviours for the total sample and by gender and racial/ethnic group. The sample was evenly distributed by race/ethnicity; $59.4 \%$ were males. Of the 964 cigarette smokers, $69.1 \%$ were daily cigarette smokers and $54.8 \%$ smoked menthol cigarettes. Stratified analysis show that a greater proportion of males (34.6\%), females $(42.8 \%)$, black/African-Americans (57.9\%) and Hispanic/Latinos (31.6\%) reported daily menthol cigarette use, while a greater proportion of whites reported daily non-menthol cigarette use $(51.8 \%$, $\mathrm{p}<0.05)$.

Twenty-seven per cent of the 964 cigarette smokers were past 30-day flavoured LCC users. Among those, the majority were male, black/African-American or Hispanic/Latino, and were menthol cigarette smokers $(46.8 \%$ were daily and $13.9 \%$ were occasional users, data not in table).
Menthol/non-menthol cigarette smoking and flavoured/ unflavoured LCC use, total sample by gender

Table 2 shows the association between menthol/non-menthol smoking frequency and flavoured/unflavoured LCC use among the total sample and stratified by gender. The adjusted model for the total sample shows that compared to occasional nonmenthol smokers, daily menthol cigarette smokers had greater odds of flavoured LCC smoking than cigarette non-LCC smoking.

\section{Gender}

Compared to occasional non-menthol smokers, male daily menthol smokers had greater odds of flavoured LCC use than cigarette, non-LCC use. Male daily non-menthol smokers also had greater odds of unflavoured and flavoured LCC use. Female daily non-menthol cigarette smokers had lower odds of unflavoured and flavoured LCC use. Female occasional menthol cigarette smokers also had lower odds of flavoured LCC use.

\section{Menthol/non-menthol cigarette smoking and flavoured/ unflavoured LCC use by race/ethnicity}

Table 3 presents the association between menthol/non-menthol cigarette smoking frequency and flavoured/unflavoured LCC use among each racial/ethnic group. Compared with occasional nonmenthol cigarette smokers, white daily menthol and nonmenthol cigarettes smokers had lower odds of unflavoured LCC use than cigarette use. Black/African-American daily menthol smokers were seven times more likely to report smoking flavoured LCCs. Hispanic/Latino daily menthol and non-menthol smokers had greater odds of flavoured LCC use.

\section{Risk perceptions of flavoured LCCs and flavoured LCC smoking status}

The distribution of respondents' perceptions of flavour additives in LCCs are presented in table 4. The top three flavour categories used among the past 30-day flavoured LCC smokers were fruit (89.7\%); candy, chocolate or other sweet (67.7\%); and menthol or mint (62.9\%). As shown in table 4 , the majority of flavoured and unflavoured LCC smokers perceived that smoking any of the LCC flavours was just as harmful as smoking a tobacco-flavoured LCC $(\mathrm{p}<0.001)$.

We examined the association between each of the risk perception variables individually and unflavoured/flavoured LCC smoking behaviour, controlling for sociodemographic factors and tobacco smoking status. Table 5 presents the associations among each of the risk perception variables and flavoured LCC smoking behaviour. Significant associations between the risk perception variables and unflavoured LCC smoking behaviour are described in text.

\section{Menthol-flavoured LCCs}

Cigarette smokers in the total sample who perceived that menthol-flavoured LCCs were less harmful to smoke were twice as likely to report flavoured LCC use. Stratified analysis found that males and black/African-Americans with positive perceptions about menthol-flavoured additives had greater odds of flavoured LCC use. Cigarette smokers in the total sample, females and Hispanics/Latinos who perceived that mentholflavoured LCCs were more harmful to smoke also had greater odds of flavoured LCC use. Hispanics/Latinos who were uncertain about the harmfulness of menthol-flavoured LCCs also had increased odds of flavoured LCC use. However, blacks/ African-Americans who were uncertain about the risks of 
Table 1 Sociodemographic characteristics and tobacco use among young and middle-aged adult current cigarette smokers, aged 18-44, USA ( $n=964$ )

\begin{tabular}{|c|c|c|c|c|c|c|c|c|c|c|c|}
\hline Characteristics & Total $(n=964)$ & Males $(n=573)$ & $\mathrm{p}$ Value & Females $(n=392)$ & $\mathrm{p}$ Value & White $(n=352)$ & $\mathrm{p}$ Value & Black/African-American $(n=299)$ & $\mathrm{p}$ Value & Hispanic/Latino $(n=313)$ & $p$ Value \\
\hline Age & & & & & & & * & & $* * *$ & & \\
\hline $18-24$ & $22.7(n=219)$ & $24.6(n=141)$ & & $19.9(n=78)$ & & $23.8(n=84)$ & & $16.5(n=49)$ & & $27.4(n=86)$ & \\
\hline $25-34$ & $43.7(n=421)$ & $43.4(n=248)$ & & $44.1(n=173)$ & & $41.7(n=147)$ & & $45.5(n=136)$ & & $44.1(n=138)$ & \\
\hline $35-44$ & $33.6(n=324)$ & $32.0(n=183)$ & & $35.9(n=141)$ & & $34.5(n=122)$ & & $38.0(n=113)$ & & $28.4(n=89)$ & \\
\hline Gender & & & & & & & & & * & & $* * *$ \\
\hline Male & $59.4(n=573)$ & - & & - & & $54.6(n=193)$ & & $56.0(n=167)$ & & $68.0(n=213)$ & \\
\hline Female & $40.6(n=392)$ & - & & - & & $45.4(n=160)$ & & $44.0(n=132)$ & & $32.0(n=100)$ & \\
\hline Race/ethnicity & & & $* * *$ & & $* * *$ & & & & & & \\
\hline White, non-Hispanic & $36.5(n=352)$ & $33.6(n=193)$ & & $40.8(n=160)$ & & - & & - & & - & \\
\hline Black/African-American, non-Hispanic & $31.0(n=299)$ & $29.2(n=167)$ & & $33.6(n=132)$ & & - & & - & & - & \\
\hline Hispanic/Latino & $32.5(n=313)$ & $37.2(n=213)$ & & $25.6(n=100)$ & & - & & - & & - & \\
\hline Educational attainment & & & & & ** & & * & & $* * *$ & & $* * *$ \\
\hline Less than high school & $25.6(n=247)$ & $23.7(n=136)$ & & $28.3(n=111)$ & & $17.5(n=62)$ & & $26.1(n=78)$ & & $34.2(n=107)$ & \\
\hline High school & $34.8(n=336)$ & $36.9(n=211)$ & & $31.9(n=125)$ & & $36.5(n=129)$ & & $35.7(n=107)$ & & $32.2(n=101)$ & \\
\hline Some college & $30.8(n=297)$ & $31.0(n=177)$ & & $30.5(n=120)$ & & $34.1(n=120)$ & & $31.5(n=94)$ & & $26.4(n=83)$ & \\
\hline Bachelor's degree or higher & $8.8(n=85)$ & $8.4(n=48)$ & & $9.3(n=37)$ & & $12.0(n=42)$ & & $6.7(n=20)$ & & $7.3(n=23)$ & \\
\hline Region of country & & & $* * *$ & & $* * *$ & & $* * *$ & & $* * *$ & & $* * *$ \\
\hline Northwest (1) & $17.9(n=173)$ & $17.8(n=102)$ & & $18.1(n=71)$ & & $17.6(n=62)$ & & $16.5(n=49)$ & & $19.5(n=61)$ & \\
\hline South (3) & $43.9(n=424)$ & $42.5(n=243)$ & & $46.0(n=180)$ & & $38.4(n=135)$ & & $55.2(n=165)$ & & $39.3(n=123)$ & \\
\hline West (4) & $17.1(n=165)$ & $19.3(n=110)$ & & $13.9(n=54)$ & & $14.3(n=50)$ & & $6.8(n=20)$ & & $30.0(n=94)$ & \\
\hline Annual household income & & & & & & & & & $* * *$ & & \\
\hline$<\$ 15000$ & $29.8(n=272)$ & $27.1(n=147)$ & & $33.7(n=125)$ & & $21.8(n=77)$ & & $47.8(n=129)$ & & $22.9(n=67)$ & \\
\hline$\$ 15000-\$ 40000$ & $30.8(n=281)$ & $27.5(n=149)$ & & $35.6(n=132)$ & & $31.8(n=112)$ & & $26.1(n=70)$ & & $33.7(n=99)$ & \\
\hline$\$ 40000-\$ 75000$ & $22.1(n=202)$ & $24.0(n=130)$ & & $19.2(n=71)$ & & $23.5(n=83)$ & & $15.8(n=42)$ & & $26.1(n=77)$ & \\
\hline$\$ 75000$ or more & $17.4(n=159)$ & $21.4(n=116)$ & & $11.6(n=43)$ & & $22.9(n=81)$ & & $10.3(n=28)$ & & $17.4(n=51)$ & \\
\hline Current employment status & & & & & & & & & $* * *$ & & \\
\hline Working & $56.9(n=549)$ & $62.6(n=358)$ & & $48.7(n=191)$ & & $64.7(n=228)$ & & $52.3(n=156)$ & & $52.5(n=165)$ & \\
\hline Not working, looking & $20.5(n=198)$ & $22.2(n=127)$ & & $18.1(n=71)$ & & $14.6(n=51)$ & & $26.3(n=79)$ & & $21.8(n=68)$ & \\
\hline Not working, not looking & $22.5(n=217)$ & $15.2(n=87)$ & & $33.2(n=130)$ & & $20.7(n=73)$ & & $21.4(n=64)$ & & $25.6(n=80)$ & \\
\hline Menthol smoking frequency & & & * & & * & & $* * *$ & & $* * *$ & & $* * *$ \\
\hline Daily menthol & $37.9(n=366)$ & $34.6(n=198)$ & & $42.8(n=168)$ & & $26.6(n=94)$ & & $57.9(n=173)$ & & $31.6(n=99)$ & \\
\hline Daily non-menthol & $31.2(n=301)$ & $31.7(n=182)$ & & $30.5(n=119)$ & & $51.8(n=183)$ & & $9.3(n=28)$ & & $28.9(n=91)$ & \\
\hline Occasional menthol & $16.9(n=163)$ & $18.4(n=106)$ & & $14.7(n=57)$ & & $8.5(n=30)$ & & $23.7(n=71)$ & & $19.8(n=62)$ & \\
\hline Occasional non-menthol & $14.0(n=135)$ & $15.3(n=88)$ & & $12.0(n=47)$ & & $13.1(n=46)$ & & $9.0(n=27)$ & & $19.7(n=62)$ & \\
\hline Current flavoured LCC product use & & & * & & * & & $* * *$ & & $* * *$ & & $* * *$ \\
\hline Cigarette, no LCC use & $64.5(n=623)$ & $56.4(n=351)$ & & $43.6(n=271)$ & & $48.7(n=303)$ & & $26.6(n=166)$ & & $24.7(n=154)$ & \\
\hline Other tobacco use & & & $* * *$ & & $* * *$ & & $* * *$ & & $* * *$ & & $* * *$ \\
\hline Yes & $33.3(n=314)$ & $34.2(n=192)$ & & $31.8(n=122)$ & & $29.8(n=102)$ & & $32.3(n=95)$ & & $37.9(n=117)$ & \\
\hline No & $66.7(n=631)$ & $65.8(n=370)$ & & $68.2(n=261)$ & & $70.2(n=239)$ & & $67.7(n=200)$ & & $62.1(n=191)$ & \\
\hline
\end{tabular}




\begin{tabular}{|c|c|c|c|c|c|c|}
\hline \multirow[b]{2}{*}{ Characteristics } & \multicolumn{2}{|l|}{ Total } & \multicolumn{2}{|l|}{ Males } & \multicolumn{2}{|l|}{ Females } \\
\hline & Unflavoured LCC use & Flavoured LCC use & Unflavoured LCC use & Flavoured LCC use & Unflavoured LCC use & Flavoured LCC use \\
\hline \multicolumn{7}{|l|}{ Menthol smoking frequency } \\
\hline Daily menthol & 1.13 (0.53 to 2.42$)$ & $1.75(1.02 \text { to } 2.98)^{*}$ & $2.33(0.78$ to 6.97$)$ & $3.67(1.78 \text { to } 7.59)^{* * *}$ & $0.29(0.07$ to 1.17$)$ & $0.43(0.16$ to 1.13$)$ \\
\hline Daily non-menthol & 1.07 (0.47 to 2.42$)$ & $1.08(0.62$ to 1.91$)$ & $3.42(1.06 \text { to } 11.05)^{*}$ & $2.96(1.37 \text { to } 6.40)^{* *}$ & $0.10(0.03 \text { to } 0.53)^{* *}$ & $0.24(0.09 \text { to } 0.66)^{* *}$ \\
\hline Occasional menthol & 0.79 (0.33 to 1.89$)$ & 0.66 (0.35 to 1.22$)$ & 0.77 (0.18 to 3.25$)$ & 0.88 (0.40 to 1.93$)$ & 0.58 (0.13 to 2.57$)$ & $0.29(0.09 \text { to } 0.93)^{*}$ \\
\hline Occasional non-menthol & Reference & Reference & Reference & Reference & Reference & Reference \\
\hline \multicolumn{7}{|l|}{ Current other tobacco use } \\
\hline No & Reference & Reference & Reference & Reference & Reference & Reference \\
\hline Yes & $1.58(0.92$ to 2.72$)$ & $3.92(2.72 \text { to } 5.64)^{* * *}$ & 1.40 (0.66 to 4.15$)$ & 1.07 (0.56 to 2.03$)$ & $1.18(0.70$ to 4.71$)$ & $2.88(1.56 \text { to } 5.34)^{* * *}$ \\
\hline \multicolumn{7}{|l|}{ Age } \\
\hline $18-24$ & Reference & Reference & Reference & Reference & Reference & Reference \\
\hline $25-34$ & $0.90(0.48$ to 1.69$)$ & $0.36(0.23 \text { to } 0.56)^{* * *}$ & 0.98 (0.41 to 2.38$)$ & $0.34(0.19 \text { to } 0.60)^{* * *}$ & 0.78 (0.22 to 2.68$)$ & $0.52(0.23$ to 1.14$)$ \\
\hline $35-44$ & 0.59 (0.29 to 1.18$)$ & $0.41(0.25 \text { to } 0.66)^{* * *}$ & $0.78(0.29$ to 2.11$)$ & $0.25(0.14 \text { to } 0.48)^{* * *}$ & $0.57(0.15$ to 2.10$)$ & $0.35(0.15 \text { to } 0.82)^{*}$ \\
\hline \multicolumn{7}{|l|}{ Race/ethnicity } \\
\hline White, non-Hispanic & Reference & Reference & Reference & Reference & Reference & Reference \\
\hline Black, non-Hispanic & $6.54(3.25 \text { to } 13.17)^{* * *}$ & $8.56(5.02 \text { to } 14.59)^{* * *}$ & $7.70(3.13 \text { to } 18.92)^{* * *}$ & $18.54(8.50 \text { to } 40.41)^{* * *}$ & $8.21(1.74 \text { to } 38.69)^{* *}$ & $8.39(3.39 \text { to } 20.75)^{* * *}$ \\
\hline Hispanic & $4.16(2.10 \text { to } 8.23)^{* * *}$ & $8.67(5.32 \text { to } 14.13)^{* * *}$ & 2.31 (0.91 to 5.87 ) & $16.26(7.96 \text { to } 33.18)^{* * *}$ & $14.39(3.75 \text { to } 55.16)^{* * *}$ & $7.06(3.14 \text { to } 15.89)^{* * *}$ \\
\hline \multicolumn{7}{|l|}{ Gender } \\
\hline Male & 1.54 (0.94 to 2.52$)$ & 1.37 (0.96 to 1.97$)$ & - & - & - & - \\
\hline Female & Reference & Reference & Reference & Reference & Reference & Reference \\
\hline \multicolumn{7}{|l|}{ Annual household income } \\
\hline$<\$ 15000$ & $0.77(0.33$ to 1.80$)$ & $0.38(0.22 \text { to } 0.68)^{* * *}$ & 0.69 (0.21 to 2.11$)$ & $0.63(0.30$ to 1.31$)$ & $0.38(0.05$ to 3.19$)$ & $0.12(0.04 \text { to } 0.38)^{*}$ \\
\hline$\$ 15000-\$ 40000$ & 0.92 (0.41 to 2.08$)$ & $0.54(0.32 \text { to } 0.92)^{*}$ & 0.89 (0.32 to 2.46$)$ & $0.45(0.22 \text { to } 0.91)^{*}$ & 0.81 (0.11 to 6.01$)$ & $0.33(0.12 \text { to } 0.89)^{* * *}$ \\
\hline$\$ 40000-\$ 75000$ & 0.93 (0.40 to 2.18$)$ & $0.35(0.20 \text { to } 0.62)^{* * *}$ & $1.03(0.37$ to 2.83$)$ & $0.36(0.18 \text { to } 0.75)^{* *}$ & 0.71 (0.08 to 5.98$)$ & $0.21(0.07 \text { to } 0.67)^{* * *}$ \\
\hline$\$ 75000$ or more & Reference & Reference & Reference & Reference & Reference & Reference \\
\hline \multicolumn{7}{|l|}{ Educational attainment } \\
\hline Less than high school & 1.52 (0.48 to 4.84$)$ & $1.24(0.62$ to 2.51$)$ & $1.20(0.28$ to 5.19$)$ & $1.71(0.65$ to 4.53$)$ & $5.91(0.43$ to 80.34$)$ & $1.58(0.51$ to 4.84$)$ \\
\hline High school & $1.72(0.57$ to 5.23$)$ & $0.98(0.49$ to 1.94$)$ & 0.91 (0.23 to 3.62$)$ & $1.71(0.67$ to 4.40$)$ & $9.43(0.71$ to 124.39$)$ & 0.82 (0.26 to 2.59$)$ \\
\hline Some college & $1.65(0.55$ to 5.00$)$ & 1.05 (0.54 to 2.05$)$ & 1.62 (0.43 to 6.06$)$ & 1.16 (0.45 to 2.94$)$ & 3.94 (0.29 to 54.11$)$ & $1.52(0.55$ to 4.23$)$ \\
\hline Bachelor's degree or higher & Reference & Reference & Reference & Reference & Reference & Reference \\
\hline \multicolumn{7}{|l|}{ Current employment status } \\
\hline Working & Reference & Reference & Reference & Reference & Reference & Reference \\
\hline Not working, looking & $1.13(0.59$ to 2.15$)$ & $0.86(0.53$ to 1.39$)$ & 1.43 (0.58 to 3.49$)$ & $0.50(0.25 \text { to } 0.969)^{*}$ & 0.71 (0.18 to 2.69$)$ & $1.17(0.52$ to 2.62$)$ \\
\hline Not working, not looking & $1.85(1.00 \text { to } 3.39)^{*}$ & 1.08 (0.68 to 1.72$)$ & 1.66 (0.66 to 4.15$)$ & 1.07 (0.56 to 2.03$)$ & 2.42 (0.86 to 6.85$)$ & 1.27 (0.61 to 2.63$)$ \\
\hline
\end{tabular}


Table 3 Multivariate analysis of menthol/non-menthol smoking frequency and flavoured/unflavoured LCC use by race/ethnicity

\begin{tabular}{|c|c|c|c|c|c|c|}
\hline \multirow[b]{2}{*}{ Characteristics } & \multicolumn{2}{|l|}{ Whites } & \multicolumn{2}{|c|}{ Blacks/African-Americans } & \multicolumn{2}{|l|}{ Latinos/Hispanics } \\
\hline & Unflavoured LCC use & Flavoured LCC use & Unflavoured LCC use & Flavoured LCC use & Unflavoured LCC use & Flavoured LCC use \\
\hline \multicolumn{7}{|l|}{ Menthol smoking frequency } \\
\hline Daily menthol & $0.16(0.03 \text { to } 0.97)^{*}$ & 0.45 (0.11 to 1.74$)$ & - & $7.29(1.91 \text { to } 27.80)^{* *}$ & 0.74 (0.17 to 3.18$)$ & $3.01(1.33 \text { to } 6.85)^{* *}$ \\
\hline Daily non-menthol & $0.11(0.02 \text { to } 0.68)^{*}$ & 0.40 (0.11 to 1.45$)$ & - & $4.72(0.83$ to 26.76$)$ & 1.07 (0.26 to 4.36$)$ & $2.44(1.07 \text { to } 5.56)^{*}$ \\
\hline Occasional menthol & 0.61 (0.08 to 4.51$)$ & 0.74 (0.15 to 3.64$)$ & - & 2.10 (0.49 to 9.00$)$ & 0.89 (0.19 to 4.26$)$ & 0.69 (0.25 to 1.86$)$ \\
\hline Occasional non-menthol & Reference & Reference & Reference & Reference & Reference & Reference \\
\hline \multicolumn{7}{|l|}{ Current other tobacco use } \\
\hline No & Reference & Reference & Reference & Reference & Reference & Reference \\
\hline Yes & 0.40 (0.08 to 2.07 ) & $11.10(4.08 \text { to } 30.21)^{* * *}$ & 2.14 (0.08 to 5.75$)$ & $5.65(2.79 \text { to } 11.47)^{* * *}$ & 1.97 (0.65 to 5.98$)$ & $3.60(1.78 \text { to } 7.27)^{\star * *}$ \\
\hline \multicolumn{7}{|l|}{ Age } \\
\hline $18-24$ & Reference & Reference & Reference & Reference & Reference & Reference \\
\hline $25-34$ & $2.45(0.46$ to 12.95$)$ & $0.18(0.06 \text { to } 0.52)^{* *}$ & $0.06(0.01 \text { to } 0.23)^{* * *}$ & $0.12(0.04 \text { to } 0.38)^{* \star *}$ & 4.71 (0.82 to 27.09$)$ & $0.31(0.14 \text { to } 0.70)^{* *}$ \\
\hline $35-44$ & 0.34 (0.04 to 3.24$)$ & $0.14(0.04 \text { to } 0.50)^{* *}$ & $0.09(0.02 \text { to } 0.37)^{* * *}$ & $0.26(0.09 \text { to } 0.78)^{*}$ & $2.24(0.36$ to 14.04$)$ & $0.26(0.11 \text { to } 0.61)^{* *}$ \\
\hline \multicolumn{7}{|l|}{ Gender } \\
\hline Male & 1.57 (0.35 to 7.06$)$ & $0.52(0.21$ to 1.31$)$ & $3.54(1.37 \text { to } 9.12)^{*}$ & 1.38 (0.68 to 2.79 ) & 0.51 (0.20 to 1.33 ) & $1.93(1.00 \text { to } 3.72)^{*}$ \\
\hline Female & Reference & Reference & Reference & Reference & Reference & Reference \\
\hline \multicolumn{7}{|l|}{ Annual household income } \\
\hline$<\$ 15000$ & $0.15(0.02$ to 1.25$)$ & $1.29(0.35$ to 4.77$)$ & 0.49 (0.07 to 3.62 ) & $0.03(0.01 \text { to } 0.13)^{* * *}$ & 2.83 (0.36 to 22.44$)$ & 3.36 (1.25 to 9.05$)$ \\
\hline$\$ 15000-\$ 40000$ & $0.10(0.02$ to 0.59$)$ & $0.46(0.14$ to 1.46$)$ & $1.58(0.22$ to 11.17$)$ & $0.23(0.06 \text { to } 0.90)^{* * *}$ & 4.85 (0.71 to 33.36$)$ & 1.35 (0.52 to 3.51$)$ \\
\hline$\$ 40000-\$ 75000$ & 0.20 (0.04 to 0.94$)$ & $0.46(0.12$ to 1.77$)$ & 0.56 (0.07 to 4.66$)$ & $0.13(0.03 \text { to } 0.55)^{* * *}$ & 2.44 (0.35 to 16.77$)$ & $0.89(0.36$ to 2.19$)$ \\
\hline$\$ 75000$ or more & Reference & Reference & Reference & Reference & Reference & Reference \\
\hline \multicolumn{7}{|l|}{ Educational attainment } \\
\hline Less than high school & - & $1.60(0.254$ to 10.86$)$ & 0.16 (0.02 to 1.28$)$ & $0.22(0.05 \text { to } 0.99)^{*}$ & $2.94(0.22$ to 38.85$)$ & 3.10 (0.99 to 9.70$)$ \\
\hline High school & $23.09(1.37 \text { to } 388.39)^{*}$ & 3.52 (0.59 to 20.88 ) & 0.31 (0.04 to 2.36$)$ & 0.70 (0.17 to 2.80$)$ & 2.36 (0.21 to 32.01$)$ & 0.41 (0.13 to 1.31$)$ \\
\hline Some college & $6.67(0.38$ to 116.27$)$ & $2.69(0.50$ to 14.33$)$ & 0.66 (0.10 to 4.54 ) & 0.44 (0.11 to 1.77 ) & $1.12(0.09$ to 14.39$)$ & 0.93 (0.30 to 2.85$)$ \\
\hline Bachelor's degree or higher & Reference & Reference & Reference & Reference & Reference & Reference \\
\hline \multicolumn{7}{|l|}{ Current employment status } \\
\hline Working & Reference & Reference & Reference & Reference & Reference & Reference \\
\hline Not working, looking & 0.47 (0.08 to 2.62$)$ & $0.90(0.25$ to 3.21$)$ & 1.69 (0.52 to 5.52$)$ & 1.91 (0.79 to 4.65$)$ & $0.26(0.04$ to 1.60$)$ & $0.36(0.15 \text { to } 0.86)^{* * *}$ \\
\hline Not working, not looking & 0.38 (0.03 to 4.64$)$ & $1.21(0.37$ to 3.95$)$ & $3.76(1.16 \text { to } 12.11)^{*}$ & $1.28(0.51$ to 3.24$)$ & 2.09 (0.58 to 7.52$)$ & $0.64(0.29$ to 1.40$)$ \\
\hline
\end{tabular}




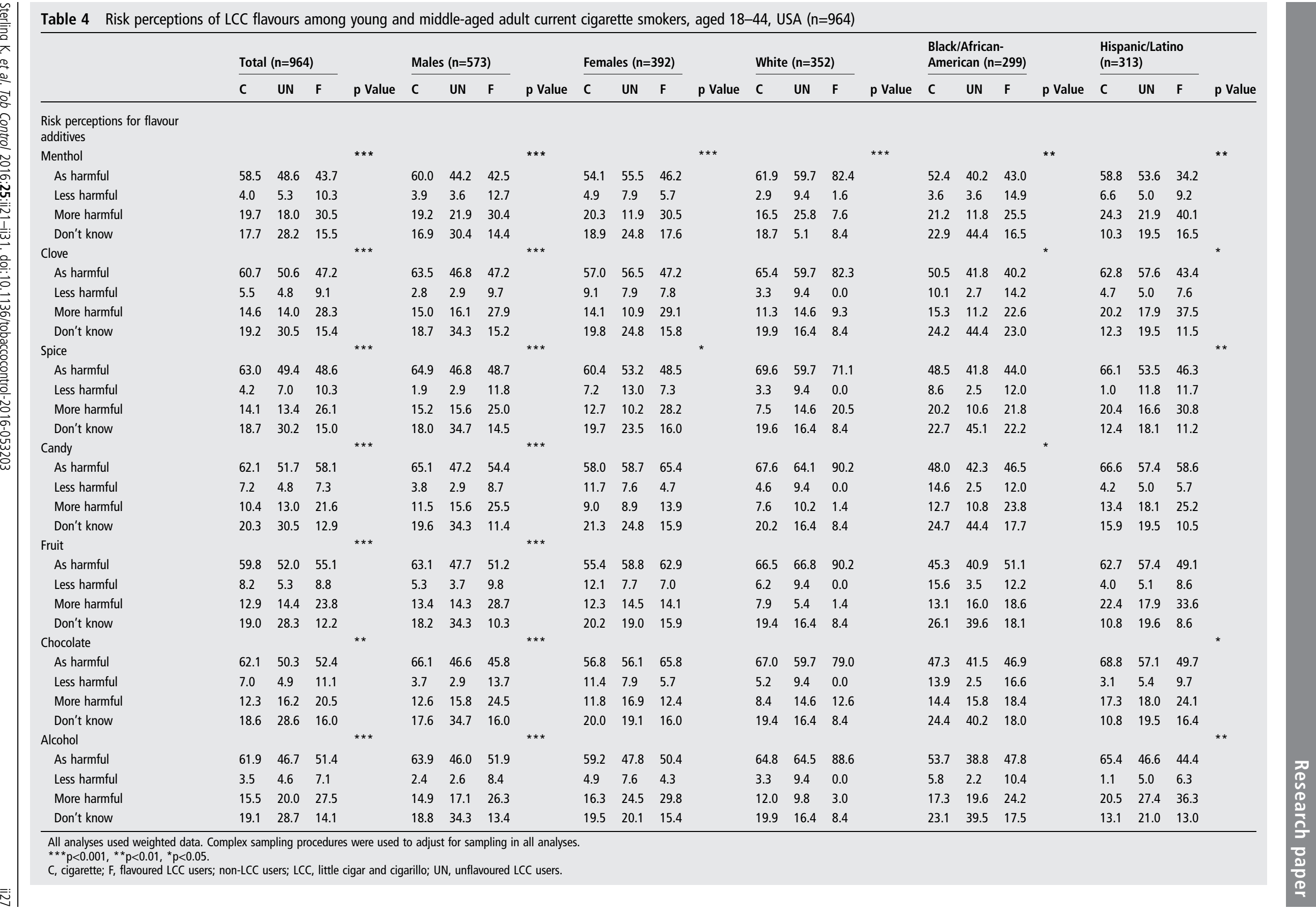


menthol-flavoured LCCs had increased odds of unflavoured LCC use (OR=3.26, 95\% CI 1.07 to 9.91).

\section{Clove-flavoured LCCS}

Cigarette smokers in the total sample, males and Hispanic/ Latinos who perceived that clove-flavoured LCCs were less harmful to smoke had greater odds of flavoured LCC use. Cigarette smokers in the total sample and Hispanics/Latinos who perceived that clove-flavoured LCCs were more harmful to smoke also had increased odds of flavoured LCC use. Hispanics/ Latinos who were unsure about the risks of clove-flavoured LCCs also had increased odds of flavoured LCC smoking. However, blacks/African-Americans who were uncertain about the risks of clove-flavoured LCCs had increased odds of unflavoured $\mathrm{LCC}$ use $(\mathrm{OR}=3.00,95 \%$ CI 1.05 to 8.58$)$.

\section{Spice-flavoured LCCS}

Cigarette smokers in the total sample and males who perceived that spice-flavoured LCCs were less harmful, to smoke had greater odds of smoking flavoured LCCs than cigarette, non-LCCs. Cigarette smokers in the total sample, whites and Hispanics/ Latinos who perceived that spice-flavoured LCCs were more harmful to smoke also had greater odds of flavoured LCC use.

\section{Candy-flavoured, fruit-flavoured and chocolate-flavoured LCCS}

Associations between flavoured/unflavoured LCC use and risk perceptions for candy-flavoured, fruit-flavoured or chocolateflavoured LCCs were not found for the total sample. Stratified analyses found that whites who were uncertain about the risks of fruit-flavoured LCCs were less likely to report smoking flavoured LCCs. Males and Hispanics/Latinos who had positive perceptions about chocolate-flavoured LCCs had greater odds of flavoured LCC use. Hispanics/Latinos who were uncertain about the risks of chocolate-flavoured LCCs also had increased odds of flavoured LCC use.

\section{Alcohol-flavoured LCCs}

Cigarette smokers in the total sample and males who perceived that alcohol-flavoured LCCs were less harmful, to smoke had greater odds of flavoured LCC use. Cigarette smokers in the total sample and Hispanics/Latinos who perceived that alcoholflavoured LCCs were more harmful to smoke had greater odds of flavoured LCC use. Hispanics/Latinos who were unsure about the risks of alcohol-flavoured LCC use also had greater odds of flavoured LCC smoking. Blacks/African-Americans who were uncertain about the risks of alcohol-flavoured had increased odds of unflavoured LCC use $(\mathrm{OR}=2.99,95 \%$ CI 1.02 to 8.77$)$.

\section{DISCUSSION}

We found that menthol-flavoured cigarette use has an independent effect on flavoured LCC use. As hypothesised, daily menthol smoking increased the odds of dual use with flavoured LCCs among the total analytic sample, males, blacks/ African-Americans, and Hispanics/Latinos. Menthol-flavoured cigarettes were the only flavoured cigarettes not banned by the FSPTCA. Menthol, along with other flavours banned in cigarettes, are the same characterising flavours available in LCC tobacco. Our findings provide evidence to the FDA that the availability and use of menthol-flavoured cigarettes threatens the public's health by increasing the risk of dual use with flavoured LCCs among cigarette smokers. Furthermore, increased dual use of menthol-flavoured cigarettes and flavoured LCCs may further elevate disproportionate tobacco-caused morbidity and mortality among blacks/African-Americans and Hispanics.
Our data suggest that cigarette smoking frequency and menthol cigarette use have important roles in the reinforcing effects of flavoured LCC use for some groups. Daily menthol cigarette smokers had greater odds of flavoured LCC use than occasional menthol and non-menthol smokers among the total sample, males, blacks/African-Americans and Hispanics/Latinos. Additionally, daily non-menthol cigarette smokers who were male and Hispanic/Latino had greater odds of dual flavoured LCC use. Prior studies show that cigarette smoking frequency is associated with nicotine dependence. ${ }^{26}$ Furthermore, mentholflavour additives in tobacco products influence the selfadministration of nicotine. ${ }^{10}$ Perhaps daily cigarette smokers, specifically those who are menthol users, dual use with flavoured LCCs to maintain or reinforce nicotine levels. In contrast to men, women who were daily non-menthol users had lower odds of unflavoured and flavoured LCC use. It is unclear why a positive association was not found for women, since they are more likely than men to reject bitter flavours like nicotine. ${ }^{27}$ Gender differences in nicotine reinforcement have been noted; nicotine intake may be a less reinforcing consequence of tobacco smoking in women than in men. ${ }^{28}$ Future studies should investigate the potential interaction between race/ethnicity and gender for menthol cigarette and flavoured LCC use; our small sample size limited our ability to investigate this relationship.

To the best of our knowledge, this is the first study to examine the association between risk perceptions of flavour additives in LCC tobacco and flavoured LCC use among young and middle-aged adult cigarette smokers. Notably, positive perceptions for menthol-flavoured additives in LCC tobacco were associated with greater odds of dual flavoured LCC use among the total sample, males and blacks/African-Americans. Brennan et $a l^{20}$ found that positive perceptions about menthol cigarette smoking were associated with current use of menthol cigarettes and other tobacco products, including little cigars, among 1825 year olds. Our study adds to the growing body of evidence that suggests that positive perceptions of menthol-flavoured additives in tobacco products increase the risk for other flavoured tobacco product use. Further, these perceptions reinforce dual flavoured tobacco use among blacks/African-Americans, who are more likely than whites to smoke menthol cigarettes ${ }^{4}$ and are less likely to successfully quit smoking. ${ }^{29}$

Candy and fruit flavours were the most commonly reported flavours used among flavoured LCC smokers in our sample. Our prior work indicated the LCC smokers who used these flavours believed they were less harmful to smoke. ${ }^{23}$ An association between perceptions of risk of these flavour additives and LCC use was not found for the total sample, however. Positive perceptions of clove-flavour, spice-flavour and alcohol-flavour additives were associated with flavoured LCC use among the total sample. While emphasis has been placed on prohibiting candy- and fruit-flavoured LCCs because of their appeal to young people, ${ }^{30} 31$ our findings indicate that a product standard that prohibits all characterising flavours - including menthol would curtail tobacco use and protect the public's health.

Perceptions of "more harm" of smoking menthol-flavoured, clove-flavoured, spice-flavoured and alcohol-flavoured additives also were associated with increased risk of flavoured LCC use among the total sample and Hispanics. Associations between flavoured LCC use and perceptions of increased harm of smoking menthol-flavoured LCCs for women, and spiceflavoured LCCs for whites were also found. Perhaps these findings reflect respondents' optimistic bias about the flavour additives; ${ }^{18}$ though they generally perceive the flavour additives as harmful, respondents may underestimate the 


\begin{tabular}{|c|c|c|c|c|c|c|}
\hline \multirow[b]{2}{*}{ Risk perceptions of flavour additives } & \multicolumn{6}{|l|}{ Flavoured LCC use } \\
\hline & Total & Males & Females & White & Black & Hispanic \\
\hline \multicolumn{7}{|l|}{ Menthol } \\
\hline As harmful & Reference & Reference & Reference & Reference & Reference & Reference \\
\hline Less harmful & $2.42(1.22 \text { to } 4.84)^{*}$ & $2.67(1.10 \text { to } 6.46)^{*}$ & 2.44 (0.62 to 9.57$)$ & 0.15 (0.01 to 3.26$)$ & $4.76(1.23 \text { to } 18.39)^{* *}$ & 2.14 (0.70 to 6.49$)$ \\
\hline More harmful & $1.62(1.08 \text { to } 2.44)^{*}$ & 1.64 (0.96 to 2.80$)$ & $2.18(1.05 \text { to } 4.54)^{*}$ & 0.34 (0.08 to 1.43$)$ & 1.71 (0.72 to 4.04$)$ & $3.43(1.75 \text { to } 6.71)^{*}$ \\
\hline Don't know & 1.24 (0.76 to 2.02$)$ & 1.14 (0.58 to 2.25$)$ & 1.12 (0.49 to 2.54$)$ & 0.35 (0.08 to 1.53$)$ & 1.11 (0.45 to 2.75$)$ & $3.88(1.54 \text { to } 9.73)^{* *}$ \\
\hline \multicolumn{7}{|l|}{ Clove } \\
\hline As harmful & Reference & Reference & Reference & Reference & Reference & Reference \\
\hline Less harmful & $2.03(1.04 \text { to } 3.98)^{*}$ & $5.48(2.12 \text { to } 14.15)^{* *}$ & 1.09 (0.33 to 3.64$)$ & - & 2.24 (0.65 to 7.72$)$ & $5.87(1.58 \text { to } 21.84)^{* *}$ \\
\hline More harmful & $1.65(1.06 \text { to } 2.59)^{*}$ & 1.50 (0.83 to 2.72 ) & $1.77(0.80$ to 3.90$)$ & 0.48 (0.11 to 2.02 ) & 1.37 (0.56 to 3.38 ) & $2.05(1.00 \text { to } 4.19)^{*}$ \\
\hline Don't know & 1.15 (0.71 to 1.86$)$ & 1.14 (0.58 to 2.20$)$ & 0.91 (0.40 to 2.06 ) & 0.27 (0.06 to 1.18$)$ & 2.31 (0.98 to 5.43 ) & $2.83(1.10 \text { to } 7.27)^{*}$ \\
\hline \multicolumn{7}{|l|}{ Spice } \\
\hline As harmful & Reference & Reference & Reference & Reference & Reference & Reference \\
\hline Less harmful & $3.74(1.87 \text { to } 7.48)^{* *}$ & $10.65(3.75 \text { to } 30.24)^{* * *}$ & $1.73(0.48$ to 6.25$)$ & - & $3.24(0.86$ to 12.24$)$ & - \\
\hline More harmful & $1.64(1.05 \text { to } 2.57)^{*}$ & 1.38 (0.76 to 2.51$)$ & $1.98(0.90$ to 4.35$)$ & $3.34(1.00 \text { to } 11.15)^{*}$ & 0.95 (0.40 to 2.25$)$ & $2.27(1.07 \text { to } 4.83)^{*}$ \\
\hline Don't know & $1.18(0.73$ to 1.90$)$ & 1.07 (0.55 to 2.08$)$ & $1.00(0.44$ to 2.26$)$ & 0.39 (0.09 to 1.63$)$ & 2.03 (0.85 to 4.86$)$ & 2.45 (0.96 to 6.28$)$ \\
\hline \multicolumn{7}{|l|}{ Candy } \\
\hline As harmful & Reference & Reference & Reference & Reference & Reference & Reference \\
\hline Less harmful & $0.90(0.47$ to 1.73$)$ & $1.86(0.76$ to 4.54$)$ & $0.36(0.11$ to 1.25$)$ & - & $1.01(0.31$ to 3.26$)$ & $1.77(0.5$ to 6.26$)$ \\
\hline More harmful & 1.39 (0.86 to 2.26$)$ & 1.65 (0.90 to 3.06$)$ & $0.82(0.31$ to 2.16$)$ & 0.14 (0.01 to 3.13 ) & 1.51 (0.61 to 3.75$)$ & 1.55 (0.69 to 3.47$)$ \\
\hline Don't know & $0.67(0.41$ to 1.10$)$ & $0.70(0.35$ to 1.40$)$ & $0.59(0.27$ to 1.29$)$ & $0.23(0.05$ to 1.00$)$ & 1.05 (0.43 to 2.55$)$ & $1.08(0.45$ to 2.59$)$ \\
\hline \multicolumn{7}{|l|}{ Fruit } \\
\hline As harmful & Reference & Reference & Reference & Reference & Reference & Reference \\
\hline Less harmful & 0.90 (0.48 to 1.67$)$ & 1.62 (0.70 to 3.75$)$ & 0.40 (0.13 to 1.24$)$ & - & 0.71 (0.22 to 2.32 ) & 2.18 (0.64 to 7.37$)$ \\
\hline More harmful & $1.16(0.73$ to 1.83$)$ & 1.45 (0.80 to 2.66$)$ & $0.56(0.22$ to 1.41$)$ & 0.09 (0.00 to 1.99$)$ & 1.09 (0.43 to 2.76$)$ & 1.09 (0.55 to 2.17$)$ \\
\hline Don't know & 0.75 (0.45 to 1.24$)$ & 0.67 (0.32 to 1.38 ) & 0.63 (0.28 to 1.42$)$ & $0.22(0.05 \text { to } 0.96)^{*}$ & 0.81 (0.34 to 1.92$)$ & 1.67 (0.63 to 4.44$)$ \\
\hline \multicolumn{7}{|l|}{ Chocolate } \\
\hline As harmful & Reference & Reference & Reference & Reference & Reference & Reference \\
\hline Less harmful & 1.80 (0.98 to 3.32$)$ & $4.32(1.83 \text { to } 10.22)^{* *}$ & 0.51 (0.15 to 1.67 ) & - & $1.73(0.57$ to 5.20$)$ & $5.71(1.57 \text { to } 20.76)^{* *}$ \\
\hline More harmful & 1.35 (0.84 to 2.17 ) & 1.82 (0.98 to 3.38$)$ & 0.67 (0.26 to 1.68$)$ & 1.39 (0.38 to 5.09$)$ & 1.11 (0.44 to 2.82 ) & 1.36 (0.63 to 2.93$)$ \\
\hline Don't know & 1.25 (0.78 to 2.00$)$ & 1.55 (0.82 to 2.95$)$ & 0.69 (0.31 to 1.55$)$ & 0.29 (0.07 to 1.28$)$ & 1.04 (0.43 to 2.49$)$ & $3.56(1.49 \text { to } 8.50)^{* *}$ \\
\hline \multicolumn{7}{|l|}{ Alcohol } \\
\hline As harmful & Reference & Reference & Reference & Reference & Reference & Reference \\
\hline Less harmful & $2.54(1.19 \text { to } 5.41)^{*}$ & $3.46(1.26 \text { to } 9.52)^{*}$ & 1.35 (0.30 to 6.04$)$ & - & 4.04 (0.98 to 16.68$)$ & - \\
\hline More harmful & $1.60(1.04 \text { to } 2.47)^{*}$ & 1.59 (0.89 to 2.84$)$ & 1.80 (0.84 to 3.88$)$ & 0.16 (0.02 to 1.35$)$ & 1.34 (0.57 to 3.13$)$ & $2.75(1.35 \text { to } 5.63)^{* *}$ \\
\hline Don't know & 1.03 (0.64 to 1.67$)$ & 0.91 (0.48 to 1.75$)$ & 0.91 (0.40 to 2.07 ) & $0.21(0.05 \text { to } 0.94)^{*}$ & 1.19 (0.50 to 2.87$)$ & $3.33(1.35 \text { to } 8.22)^{* *}$ \\
\hline $\begin{array}{l}\text { All analyses used weighted data. Complex } \\
\text { The referent group for the risk perception } \\
\text { The referent group for the outcome, LCC u } \\
\text { Dashed lines represent no or inflated point } \\
{ }^{* * *} p<0.001,{ }^{* *} p<0.01,{ }^{*} p<0.05 \text {. } \\
\text { LCC, little cigar and cigarillo. }\end{array}$ & $\begin{array}{l}\text { procedures were used to } \\
\text { as harmful. } \\
\text { arette, non-LCC use. } \\
\text { s that resulted from mode }\end{array}$ & $\begin{array}{l}\text { r sampling in all analyses. } \\
\text { ad small subgroup sample siz }\end{array}$ & & & & \\
\hline
\end{tabular}


likelihood they will experience adverse events and are more likely to smoke flavoured LCCs. Findings should be interpreted with caution.

Regarding study limitations, our data are self-reported and cross-sectional. Temporal associations cannot be determined. Use of other forms of tobacco (ie, smokeless and pipe) were not assessed in our survey. Small subgroup sample sizes resulted in inflated point estimates. We did not analyse LCC use or risk perceptions by type (LCC-tobacco, LCC-blunt or LCC-polyuse). Study findings may differ depending on how respondents smoked LCCs. Data collection was not inclusive of other racial/ ethnic groups, such as American Indians, Alaska Natives, Native Hawaiians, other Pacific Islanders, and Asian aggregate and disaggregate groups. Future studies should determine the association between menthol cigarette and flavoured LCC smoking among these groups. Regarding study strengths, our current study replicated the independent association between menthol cigarette and flavoured LCC use ${ }^{13}$ and goes beyond prior work by demonstrating that black/African-American and Hispanic/ Latino daily menthol cigarette smokers had greater odds of flavoured LCC use.

Our findings suggest that the availability of menthol and other flavoured additives in tobacco products influences young and middle-aged adult cigarette smokers' perception of risk and dual use of flavoured LCCs, particularly smokers from black/ African-American and Hispanic/Latino communities who are targeted by tobacco industry marketing and disproportionately suffer from tobacco-related morbidity and mortality. The FDA's landmark decision to extend it regulatory authority to LCCs was a critical step towards protecting the public's health. Our data add to the body of scientific evidence that would support an FDA ban on all characterising flavours-including menthol-in all tobacco products. Over $60 \%$ of flavoured LCC smokers in our sample smoked menthol-flavoured cigarettes. A characterising flavour ban that excludes menthol-flavoured products may promote continued tobacco use among some vulnerable populations.

\section{What this paper adds}

- Menthol flavoured cigarettes and flavoured little cigars and cigarillos (LCCS) are currently unregulated by the Food and Drug Administration (FDA), which has provided the tobacco industry with an unobstructed opportunity to market these products.

- Flavour additives in cigarettes and LCCs, which influence smokers' risk perceptions, may reinforce flavoured LCC use.

- The association of menthol cigarette smoking and risk perceptions about flavoured additives in LCC tobacco with the current use of flavoured versus unflavoured LCCs is unknown.

- Increasing our understanding of this relationship may help us further understand the potential underlying mechanisms by which the use of a flavoured tobacco product influences other flavoured tobacco product use.

- Our study found that daily menthol cigarette smoking is associated with greater odds of flavoured LCC use among a national probability sample of black/African-American, Hispanic/Latino, and white young and middle-aged adult cigarette smokers.

- Our data add to the body of scientific evidence that supports the FDA's ban of all characterising flavours in LCCs.
Contributors KS conceived the study, obtained study funding, and was responsible for data collection and analysis and manuscript preparation and writing. CF contributed the study's methodological development, manuscript preparation and provided detailed feedback on all manuscript drafts. IP contributed to the study's data analysis and interpretation and provided detailed feedback on all manuscript drafts. DJ provided detailed feedback on all manuscript drafts. PF contributed the study's methodological development, data analysis and interpretation, manuscript preparation, and provided detailed feedback on all manuscript drafts.

Funding This study was supported by the National Institutes of Health/National Cancer Institute (NIH/NCI) and the FDA Center for Tobacco Products (CTP), grant number 1R21CA180934-01 (PI Sterling). Dr. Fryer was supported, in part, by his NCl-funded Career Development Award (K01CA148789).

Competing interests None declared.

Ethics approval Georgia State University Institutional Review Board.

Provenance and peer review Not commissioned; externally peer reviewed.

Data sharing statement Only members of the research team working on this project have access to the data in this study. Findings obtained from the research will be shared with the scientific community through peer-reviewed manuscripts, presentations at scientific conferences and through NIH or FDA's Center for Tobacco Products progress reports.

\section{REFERENCES}

1 Tobacco Products Scientific Advisory Committee. Tobacco Products Scientific Advisory Committee Menthol Cigarettes and Public Health: Review of the Scientific Evidence and Recommendations. http://www.fda.gov/downloads/Advisory Committees/CommitteesMeetingMaterials/TobaccoProductsScientificAdvisory Committee/UCM269697.pdf. Published 2011. (accessed 17 Apr 2016).

2 U. S. Food and Drug Administration. Deeming tobacco products to be subject to the federal food, drug, and cosmetic act, as amended by the family smoking prevention and tobacco control act; restrictions on the sale and distribution of tobacco products and required warning statements for tobacco products. Final rule. Fed Regist 2016:81:28973-9106.

3 Tobacco Control Legal Consortium. The Deeming Regulation: FDA authority over e-cigarettes, cigars, and other tobacco products. 2016. http://publichealthlawcenter. org/sites/default/files/resources/tclc-fda-deemingreg-regulation-authority-2016.pdf (accessed 31 Aug 2016).

4 Giovino GA, Villanti AC, Mowery PD, et al. Differential trends in cigarette smoking in the USA: is menthol slowing progress? Tob Control 2015;24:28-37.

5 Corey CG, King BA, Coleman BN, et al. Little filtered cigar, cigarillo, and premium cigar smoking among adults_-United States, 2012-2013. MMWR Morb Mortal Wkly Rep 2014;63:650-4.

6 Kreslake JM, Wayne GF, Connolly GN. The menthol smoker: tobacco industry research on consumer sensory perception of menthol cigarettes and its role in smoking behavior. Nicotine Tob Res 2008;10:705-15.

7 Nonnemaker J, Hersey J, Homsi G, et al. Initiation with menthol cigarettes and youth smoking uptake. Addict Abingdon Eng/ 2013;108:171-8.

8 Food and Drug Administration. Preliminary scientific evaluation of the possible public health effects of menthol versus non-menthol cigarettes. 2013. http://www. fda.gov/downloads/UCM361598.pdf. Published 2013 (accessed 17 Apr 2016).

9 Palmatier MI, Lantz JE, O'Brien LC, et al. Effects of nicotine on olfactogustatory incentives: preference, palatability, and operant choice tests. Nicotine Tob Res Off I Soc Res Nicotine Tob 2013;15:1545-54.

10 Wang $\mathrm{T}$, Wang $\mathrm{B}$, Chen $\mathrm{H}$. Menthol facilitates the intravenous self-administration of nicotine in rats. Front Behav Neurosci 2014;8:437.

11 Villanti AC, Giovino GA, Barker DC, et al. Menthol brand switching among adolescents and young adults in the National Youth Smoking Cessation Survey. Am J Public Health. 2012;102:1310-12.

12 Villanti AC, Richardson A, Vallone DM, et al. Flavored tobacco product use among U.S. Young adults. Am J Prev Med 2013;44:388-91.

13 Sterling K, Berg CJ, Thomas AN, et al. Factors associated with small cigar use among college students. Am J Health Behav 2013;37:325-33.

14 Delnevo CD, Giovenco DP, Ambrose BK, et al. Preference for flavoured cigar brands among youth, young adults and adults in the USA. Tob Control 2015;24:89-94.

15 King BA, Dube SR, Tynan MA. Flavored cigar smoking among U.S. adults: findings from the 2009-2010 National Adult Tobacco Survey. Nicotine Tob Res Off I Soc Res Nicotine Tob 2013;15:608-14.

16 Williams JA, Bartoshuk LM, Fillingim RB, et al. Exploring ethnic differences in taste perception. Chem Senses 2016;41:449-56.

17 Backinger CL, Meissner H, Ashley DL. The FDA "deeming rule" and tobacco regulatory research. Tob Regul Sci 2016;2:290-3.

18 Weinstein $N$. What does it mean to understand a risk? Evaluating risk comprehension. J Natl Cancer Inst 1999;25:15-20.

19 Kreuter MW, Strecher VJ. Changing inaccurate perceptions of health risk: results from a randomized trial. Health Psychol Off I Div Health Psychol Am Psychol Assoc 1995;14:56-63. 
20 Brennan E, Gibson L, Momjian A, et al. Are young people's beliefs about menthol cigarettes associated with smoking-related intentions and behaviors? Nicotine Tob Res Off I Soc Res Nicotine Tob 2015;17:81-90.

21 GfK. KnowledgePanel Design Summary. http://www.knowledgenetworks.com/ knpanel/docs/knowledgepanel(R)-design-summary-description.pdf (accessed 20 Aug 2016).

22 National Cancer Institute-Cancer Control and Population Sciences. http:/l cancercontrol.cancer.gov/brp/tcrb/tus-cps/ (accessed 31 Aug 2016).

23 Sterling $\mathrm{K}$, Fryer C, Nix M, et al. Appeal and impact of characterizing flavors on young adult small cigar use. Tob Regul Sci 2015;1:42-53.

24 Sterling KL, Fryer CS, Fagan P. The most natural tobacco used: a qualitative investigation of young adult smokers' risk perceptions of flavored little cigars and cigarillos. Nicotine Tob Res 2016;18:827-33.

25 Bryant F. Assessing the measurement validity. In: Reading and understanding more multivariate statistics. Washington DC: American Psychological Association, 2002:99-146.

26 Centers for Disease Control Office on Smoking and Health. 2010 Surgeon General's Report: how tobacco smoke causes disease: the biology and behavioral basis for smoking-attributable disease. http://www.cdc.gov/tobacco/data_statistics/sgr/2010/ (accessed 28 Aug 2016).

27 Bartoshuk LM, Duffy VB, Miller IJ. PTC/PROP tasting: anatomy, psychophysics, and sex effects. Physiol Behav 1994;56:1165-71.

28 Perkins KA, Donny E, Caggiula AR. Sex differences in nicotine effects and self-administration: review of human and animal evidence. Nicotine Tob Res 1999;1:301-15

29 U.S. Department of Health and Human Services. Tobacco use among U.S. racial/ ethnic minority groups: African Americans, American Indians and Alaskan Natives, Asian Americans and Pacific Islanders, and Hispanics. A Report of the Surgeon General. Atlanta: U.S. Department of Health and Human Services, Centers for Disease Control and Prevention, National Center for Chronic Disease Prevention and Health Promotion, Office on Smoking and Health 1998.

30 Ashare RL, Hawk LW, Cummings KM, et al. Smoking expectancies for flavored and non-flavored cigarettes among college students. Addict Behav 2007;32:1252-61.

31 Klein S, Giovino GA, Barker D, et al. Use of flavored cigarettes among older adolescents and adult smokers: United States, 2004-2005. Nicotine Tob Res 2008;10:1209-14. 